\title{
Article Delivery Service
}

Our abstracting service is intended to provide the flavour of the best and most relevant articles we have found in contemporary publications. This is no substitute for reading the original, where it is relevant to your concerns, therefore:

The IDM Knowledge Centre can deliver, by post or fax, a copy of most of the articles abstracted, delivery is FREE to IDM members; non-members pay a handling fee of $£ 15$ per article with a maximum handling fee for any one order of $£ 60$.

The law in the UK requires that you sign a copyright declaration before copies can be despatched:

- If the article is for non-commercial research or for private study, no copyright fee is payable, but you may only have one article from each lettered group below.

- If the article is for a commercial purpose the appropriate copyright fee must be paid - fees are given next to the abstract number below.

- For help in deciding whether your purpose is commercial or non-commercial, please contact the IDM Knowledge Centre, or look at the guidance provided by the British Library at www.bl.uk/ services/information/copyrightfaq.html

\section{To order}

When you know whether your purpose is commercial or not, ask the Knowledge Centre to e-mail, fax or post you the appropriate order form.

\section{Contacting the IDM Knowledge Centre}

Telephone: +44(0)2086140253

E-mail: $\quad$ knowledgecentre@theidm.com

Post: $\quad$ Knowledge Centre, IDM, 1 Park Road, Teddington TW11 0AR, UK

The Knowledge Centre is staffed on Mondays and Tuesdays by Penny Crossland and on Wednesdays to Fridays by Anita Littler.

\section{Copyright Fees and Lettered Groups}

All fees are subject to VAT at 17.5\%. Copyright Fees correct at 16 November 2006 but may change - you pay the Fee current at the time a copy is made.

\begin{tabular}{|c|c|c|c|}
\hline $8301 £ 5$ & $8306 £ 5 C$ & 8311 £5 E & $8316 £ 13$ J \\
\hline $8302 £ 5$ & $8307 £ 5$ D & $8312 £ 5$ & $8317 £ 5 \quad K$ \\
\hline $8303 £ 17$ B & $8308 £ 5$ D & $8313 £ 5 \quad F$ & \\
\hline $8304 £ 5$ & $8309 £ 5 D$ & $8314 £ 13 G$ & \\
\hline $8305 £ 5$ & $8310 £ 5$ D & $8315 £ 22 \mathrm{H}$ & \\
\hline
\end{tabular}

$£ \mathbf{V}$ means a photocopy for commercial purpose is not available; visitors may read the article in the Knowledge Centre (by appointment, please).

$\mathbf{n} / \mathbf{a}$ means a photocopy is not available but visitors may read the article in the Knowledge Centre (by appointment, please). 